\title{
Walter White aka Heisenberg. La aparición de un icono cultural*
}

\author{
Rayco GONZÁLEZ \\ Universidad de Burgos
}

(Abstracts y palabras clave al final del artículo)

Enviado: 14 de agosto de 2015

Aceptado: 18 de agosto de 2015

\section{WALTER WHITE: UN HOMBRE LLAMADO PELIGRO}

Walter White es el producto de dos factores: por un lado, de un personaje o, incluso, de la trama de una serie televisiva de gran éxito, Breaking Bad; y, por otro, la imagen o el icono o, incluso, el hipoicono en términos peirceanos, de un actor escasamente conocido en la esfera televisiva, Bryan Cranston ${ }^{1}$.

La serie Breaking Bad se estrenó en el canal norteamericano AMC el 20 de enero de 2008 y fue creada por Vince Gilligan, conocido guionista, productor y director de series en la televisión estadounidense. Gilligan se haría conocer en la serie Expediente $X$ (The $X$ Files), donde comenzó su carrera como guionista, inicialmente, y luego como productor y director desde la segunda temporada, año de su debut, hasta el final de la misma. Su siguiente producción, The Lone Gunmen, es un spinoff de la anterior: Gilligan fue fiel a la serie de Fox Mulder y Dana Scully, como también lo es en la actualidad a Breaking Bad, gracias al reciente spin-off titulado Better Call Saul, emitida igualmente por AMC.

Breaking Bad es, por tanto, el tercer trabajo de Gilligan: una serie de sesenta y dos episodios divididos en cinco temporadas. El común denominador de su obra parece ser las historias secretas o clandestinas. Si en The X-Files se trataban de agentes secretos, en Breaking Bad la historia gira en torno a la transformación de un personaje, Walter White, cuya vida pasa de transcurrir en la "normalidad" de un hom-

\footnotetext{
* El presente artículo es fruto de las discusiones mantenidas en el seminario del Grupo de Estudios de Semiótica de la Cultura, dirigido por Jorge Lozano, y a cuyos miembros, y especialmente a Jorge Lozano, Marcello Serra y Gérald Mazzalovo, agradezco todas sus sugerencias y matizaciones.

${ }^{1}$ A pesar de su longeva edad, Bryan Cranston, nacido en Los Ángeles en 1956, apenas si tuvo un papel destacado en toda su carrera y, en la mayoría de su trabajos, se trataba de papeles secundarios, como el de la exitosa serie Malcolm in the Middle (2000-2006), donde hacía de padre de Malcolm. Solo con la serie Breaking Bad le llegará el éxito y el reconocimiento de público y de crítica.
} 
bre cualquiera de Albuquerque, a hacerlo por los clandestinos cauces de un fabricante de metanfetamina, cuyo pseudónimo será Heisenberg.

Se suma a este factor otro no menos importante: la enorme popularidad de estas series tuvo como contrapartida la generación de toda una serie de iconos en la semiosfera mediática para cuya creación se utilizaban imágenes extirpadas directamente de sus fotogramas o de partes de sus fotogramas. Posteriormente, estos iconos evolucionaban independientemente de la imagen inicial, gracias a la intervención de diseñadores y artistas gráficos, hasta el punto que algunos de ellos pasaron a convertirse en logos de la serie. Este fue el caso, por ejemplo, del intertítulo de la serie The $X$ Files.

Hoy el rostro de un tal Heisenberg, ataviado con gafas y sombrero, aparece en numerosos estampados de camisetas en todo el mundo, variando las formas de las líneas, los colores del relieve y del fondo, las tipografías de la letra, etc. Numerosos son igualmente los gadgets con su rostro: muñecos, tazas, relojes e incluso tablas de cocina $^{2}$. Es posible también personalizar los iconos de nuestro ordenador personal con las imágenes de Heisenberg. La mayoría de estas variedades iconográficas han sido elaboradas por diseñadores y artistas independientes seguidores de la serie. Se trata, por tanto, de un fenómeno de fan art, término con el que nos referimos a las obras de arte que ni se crean ni están comisionadas o aprobadas por los creadores de la obra de la que derivan.

Inicialmente la imagen con la que se inicia la fortuna iconográfica de Breaking Bad es la de Bryan Cranston, el actor que da vida al protagonista Walter White, ataviado con un sombrero aparentemente de fieltro, borde estrecho y corona plana, conocido en inglés como pork pie hat ${ }^{3}$. Esta indumentaria, conjugada muy a menudo con unas gafas de sol, son las que en realidad Walter White usa en la serie para ocultar su verdadera identidad. ¿Por qué debe hacerlo? ¿Qué le lleva a cambiar su recorrido vital hasta tener que ocultar que es quien es?

\footnotetext{
2 Coloquialmente se dice “cocinar", en inglés 'to cook', al acto de fabricar droga. Se ha extendido también una frase de la serie: 'let's cook', es decir, "vamos a cocinar".

${ }^{3}$ La historia del pork pie hat podría comenzar con Buster Keaton, quien siempre llevaba uno de estos sombreros. En el cine podemos encontrar algún que otro ejemplo aislado, como el personaje encarnado por Gene Hackman en The French Connection (1971), de William Friedkin, Jimmy 'Popeye' Doyle, un rudo y violento policía con problemas de alcoholismo. También Robert de Niro llevaba un pork pie hat en Mean Streets (Malas calles, 1973), de Martin Scorsese, representando a un jugador de pacotilla. Por mucho que nos pusiésemos a analizar estos casos, remotamente encontraremos una marca semántica que dé unidad al significado de este tipo de sombrero, cosa que, por otra parte, no es mi intención en este artículo.
} 


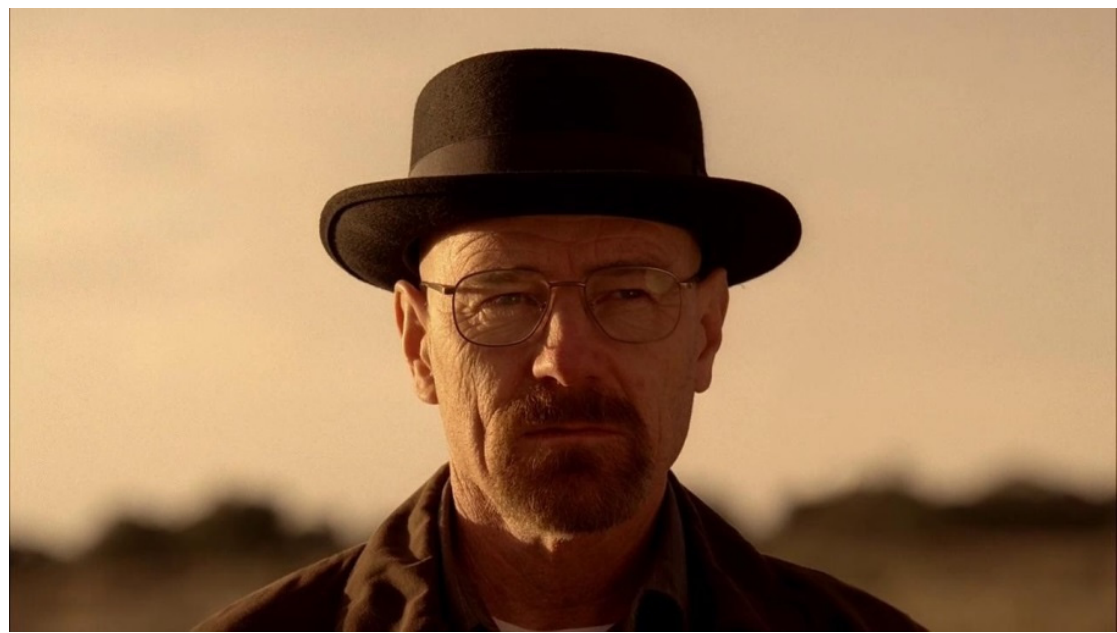

Fig. 1. Fotograma de Walter White con su pork pie hat en la serie Breaking Bad.

Retrocedamos un poco para construir un esbozo biográfico del personaje. Walter "Walt" Hartwell White es un profesor de química en un pequeño instituto de Albuquerque, Nuevo México. Walter vive una vida común junto a su mujer Skyler, embarazada de su segunda hija, Holly, y a su primogénito, Walter Jr., que sufre una parálisis cerebral. El inicio de la trama se sitúa en el quincuagésimo aniversario de Walter. A los pocos días le descubren que la tos que ha venido padeciendo es provocada por un cáncer de pulmón terminal en estado avanzado: Walter sale así de su plácida cotidianidad, pese a lo cual decide no decírselo a nadie, ni siquiera a su propia familia. Tras varias peripecias, Walter toma también otra decisión: entra en el mundo del narcotráfico para conseguir dinero con el que poder garantizar la vida de su familia después de su muerte. Todo ello ocurrirá bajo la total ignorancia de su mujer y de su hijo. Es este desvío del "normal" camino de un hombre middle class el que servirá de núcleo semántico para el título de la serie, Breaking Bad, que incluye tanto el sentido de "tomar el mal camino" o, también, el de "echarse a perder".

A la par que se desarrolla la trama, aumenta nuestro conocimiento sobre este aparente hombre común, quien en su época de estudiante fue un brillante químico que formó junto a otros dos personajes, Gretchen (su asistenta y con quien mantuvo una relación amorosa) y Elliott, una empresa, Gray Matter ${ }^{4}$.

Por razones nunca explicadas en la serie, Walter repente dejó a Gretchen durante unas vacaciones con su familia, abandonando la empresa y la investigación. Gretchen finalmente se casó con Elliot y Gray Matter se convirtió en una empresa de gran éxito gracias, fundamentalmente, a la investigación de Walter. Como consecuencia, Walter guarda un secreto rencor, ya que piensa que su obra le fue robada y culpa a Elliott y Gretchen por el sentido que tomó su vida.

${ }^{4}$ El nombre de la empresa proviene de la combinación de los apellidos de los dos fundadores, Walter White y Elliott Schwartz, que significa 'negro' en alemán. Negro y blanco ('white') combinados da gris ('gray'). 
Walter entra en el narcotráfico gracias a un antiguo estudiante del instituto donde imparte sus clases, Jesse Pinkman, quien se convertirá en socio de Walter para la fabricación de metanfetamina. Jesse era un consumidor de metanfetamina, además de fabricante y distribuidor de poca monta. De hecho, antes de su asociación con Walter elaboraba la metanfetamina añadiendo un poco de chile en polvo.

Walter se convierte, de inmediato, en el fabricante de la metanfetamina más pura, gracias a sus competencias en química, lo cual no pasa desapercibido a los grandes jefes del comercio de la droga. Walter se vincula a diferentes estructuras del contrabando, arriesgando su vida para ello en multitud de ocasiones. Aunque inicialmente Walter no es más que un padre de familia, el tiempo va ejerciendo en nuestro personaje un cambio radical. Walter toma el pseudónimo de Heisenberg ${ }^{5}$ para su recién estrenada carrera clandestina en el mundo de las drogas, para mantener oculta su verdadera identidad. A pesar de que la primera regla que Walter se da a sí mismo y a Jesse al entrar en el negocio es la de "no matar", los acontecimientos le obligan al homicidio, en repetidas circunstancias.

Walter se va haciendo cada vez más importante, desafiando en varias ocasiones el control del mercado. Paralelamente, su mujer, Skyler, desvela la vida oculta de su marido, hasta que consigue su confesión. Aunque al saberlo Skyler obliga a Walter a irse de casa, posteriormente ella decide colaborar a blanquear sus ganancias. Walter acaba trabajando para el mayor emporio de la droga en Nuevo México, dirigido por Gus Fring. Más tarde, Walter lo asesinará durante una lucha encarnizada por el poder. Mientras tanto, Skyler teme por el bienestar de la familia, a lo que Walter responde con su ya famosa frase: "No, no sabes a quién estás hablando, así que déjame aclarártelo. No estoy en peligro, Skyler. Yo soy el peligro. ¿Un hombre abre su puerta y es asesinado de un disparo y tú piensas que yo puedo ser el siguiente? No. Soy yo quien toca a la puerta".

Al final de la serie, Walter cambia de nombre nuevamente y se esconde de los sicarios que han ocupado el lugar de Gus y que secuestraron a Jesse para que fabricase metanfetamina para ellos. Walter morirá finalmente de cáncer, pero en el camino ha perdido a su familia, que se separa definitivamente de él. Antes de morir, facilitará la llegada de dinero a su mujer y sus hijos, Holly y Walter Jr., mediante la intervención de Elliott y Gretchen, y se vengará de los sicarios, liberando a Jesse y matándolos a todos.

En el último episodio de la serie, Walter reconoce a Skyler, con quien se reencuentra para poder ver por última vez a su hija Holly, que todas sus acciones no estaban determinadas por la necesidad de proveer a su familia de un sustento después de su muerte, sino por el propio placer de sentirse con el poder hacerlas. En una escena de este episodio, Walter observa su antigua casa completamente destrozada. No sabemos bien quién fue el autor ni los motivos, aunque los intuimos. Uno de los fotogramas revela la distancia entre el personaje de Walter y el de Heisenberg. Un Walter moribundo observa una de las paredes del salón cubiertas con el nombre de su alter ego, Heisenberg, en forma de acusación: sabemos que tú eres Heisenberg.

\footnotetext{
${ }^{5}$ Es inútil señalar el motivo de la selección de este pseudónimo: Werner Heisenberg (1901-1976) fue un importante físico que obtuvo el Nobel en 1932.
} 


\section{HEISENBERG, UN ICONO CULTURAL}

En el primer capítulo de la serie vemos a Walter White impartiendo una de sus clases de química en el pequeño instituto de Albuquerque. Es entonces cuando afirma: "la química es el estudio de la materia. Yo prefiero verla como el estudio del cambio". La frase es una forma de prolepsis o premonición sobre su propio devenir. Como he descrito en el epígrafe anterior, Walter, un padre de familia y profesor de instituto, se transforma en Heisenberg, un genial fabricante de droga que acaba sus días asesinando como forma de demostración de su poder. En realidad, Breaking $B a d$ es también el estudio de un cambio radical que va de Walter a Heisenberg, de ser un profesor frustrado que se enfrenta a un letal cáncer a convertirse en el mejor fabricante de metanfetamina y en un eficaz asesino capaz de escapar a la misma muerte en innumerables ocasiones.

En esta transformación vemos operarse una antinomia: Walter vs Heisenberg, o lo que es lo mismo, en términos lotmanianos "inteligente" vs "loco" (Lotman 1993: 61-95). Lotman incluye esta contraposición binaria dentro de una ternaria, en la que estaría también la figura estereotipada del tonto. Mientras que el tonto y el loco ocupan los polos extremos de esta estructura ternaria, el inteligente ocupa el espacio intermedio. Estas tres figuras se rigen por la oposición cumplimiento/incumplimiento de las normas, dentro de la poética de la cotidianidad (cfr. también Sedda 2006: 52-59). El inteligente es aquel

cuyo comportamiento es definido como normal. Piensa aquello que, según el uso, las leyes de la razón o de la expresión práctica, necesita pensar. Así su comportamiento es previsible, es descrito como norma y corresponde a las fórmulas de las leyes y a las reglas del uso (Lotman 1993: 61).

En cambio, el loco es aquel cuyo

comportamiento [es] insensato [...]. [Este comportamiento] se diferencia por la libertad posterior que este individuo tiene gracias al hecho de violar las prohibiciones, de poder cometer actos prohibidos al hombre "normal". Esto confiere a sus acciones el carácter de imprevisibilidad (ibid.).

Walter y Heisenberg son, siguiendo este modelo, las dos caras de un Jano: el inteligente o normal padre de familia y el loco fabricante de metanfetamina obligado a cometer asesinatos, a pesar de que él mismo se diera la norma de no matar al introducirse en su nueva vida clandestina. Así, la transformación de este personaje se realiza en un salto antinómico, en el paso de una alteridad absoluta, en cuya radicalidad podemos encontrar los motivos de la fascinación que ha despertado entre los espectadores ${ }^{6}$.

\footnotetext{
${ }^{6}$ Esta oposición también se da en el plano topológico. El espacio enuncivo que ocupa Walter es el espacio paratópico, que según Greimas y Courtés (1979: 300-301) es "un subcomponente del espacio tópico y opuesto al espacio utópico (en que se desarrollan las performances) - es aquel en que se desarrollan las pruebas preparatorias o calificantes y se adquieren las competencias (tanto en la dimensión pragmática como en la dimensión cognoscitiva)". Este espacio lo podríamos definir también como espacio de lo cotidiano. En cambio, el espacio utópico, lugar de la performance. De hecho, los aumentos de tensión en la serie pueden ser analizados como el constante cruce de espacios de personajes que habitan uno u otro: por ejemplo, una
} 
Heisenberg deviene así un fenómeno casi viral en la red, contemporáneamente al crecimiento de un fenómeno fan art de vastas dimensiones. La imagen que fundó esta fortuna iconográfica no fue el fotograma de la imagen real del protagonista que vemos en la figura 1. En realidad, el icono inicial es una caricatura que aparece en la misma serie, al final de la primera temporada. Por tanto, la imagen fundacional es metonímica: un fotograma que significa la totalidad de fotogramas de la serie (fig. 2). Esta imagen es el retrato que reciben dos personajes de la familia Salamanca, perteneciente al cartel Juárez que había dominado el tráfico de metanfetamina en Nuevo México hasta la llegada de Heisenberg. Ese dominio se ejercía por la presencia en Albuquerque de Tuco Salamanca, un psicótico personaje que no duda en ejercer la violencia por cualquier motivo y ante cualquier circunstancia. La caricatura (o retrato robot) la llevan consigo dos primos de Tuco enviados para matarlo tras saber que este ha sido muerto: la familia Salamanca en México cree, erróneamente, que el asesino es Heisenberg.

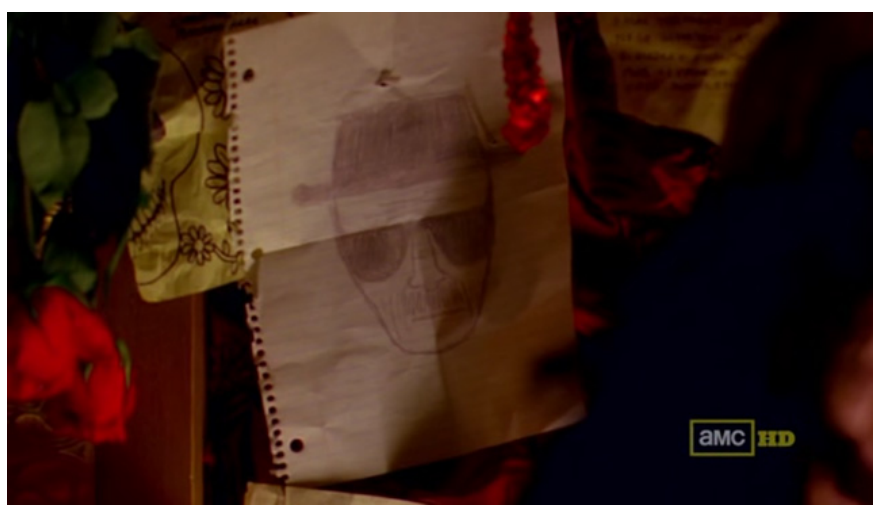

Fig. 2. El retrato robot de Heisenberg.

Son tres, por tanto, los elementos fundamentales, los tres ya mencionados en el epígrafe anterior: el pork pie hat, la gafas de sol y el bigote. Estos tres elementos parecen fundirse en la identidad de Heisenberg. De hecho serán los rasgos isográficos, con sus variantes, que determinarán la emergencia de nuevos iconos, con todas sus variantes. Podríamos definir isografía, siguiendo a Omar Calabrese (1995: 28) como la noción paralela a la de "isotopía", ya que si esta supone una coherencia de rasgos semánticos en un texto dado, y como tal remite al contenido, aquella se refiere a la coherencia en las formas expresivas, es decir, relativa al plano de la expresión. Las variantes que observamos en los otros iconos son dos: la sustitución de las gafas de sol por las gafas de lente y el bigote por una perilla (fig. 3). En el primer caso se trata estrictamente de una sustitución (al menos de las lentes); en el segun-

de las escenas de mayor tensión de toda la serie ocurre en el sexto episodio de la quinta temporada, cuando Walter invita a cenar a Jesse junto a su mujer. 
do caso es más bien una diferencia de extensión (la perilla no es más que la extensión del bigote) $)^{7}$.

Si comparamos la figura 1 con la figura 2 , observaremos que su iconicidad no es, en términos peirceanos, de un alto grado. En una escala de iconocidad (cfr. ivi: 19), esta imagen-retrato de Heisenberg sería de un grado muy bajo. Precisamente utiliza los recursos típicos de la caricatura: la acentuación de algunos rasgos característicos del sujeto retratado y la desaparición de otros ${ }^{8}$.

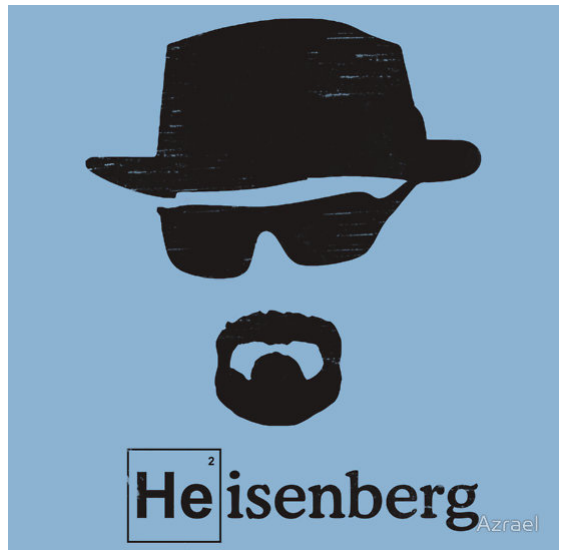

Fig. 3. Heisenberg con perilla.

La estructura perceptiva en este caso está en la trinidad de elementos que la constituyen. Esta trinidad da buena cuenta de todo el fenómeno de construcción de un icono cultural: Walter White no es interpretado en la trama que lo hace emerger, Breaking Bad, sino como un signo, en cierto grado símbolo (un ídolo) y en cierto grado icono, cuyo significado puede variar y que está sujeto a variaciones. Como en todo símbolo, la relación entre significante y significado es convencional (no hay relación inherente entre ambos) e, igualmente, el símbolo está culturalmente motivado. El significado simbólico puede variar en el tiempo, pero hay algunos rasgos que son estables en diferentes representaciones y que pueden ser reducidas a una sola fórmula que funciona como la estructura invariable. En este caso, Heisenberg condensa en su iconicidad la transformación operada en la trama de la serie.

7 Es curioso observar que Walter pasa del bigote a la perilla y termina llevando una barba prominente. Sin embargo, no encontraremos iconos con su rostro con barba; y ello se debe a la isografía que mantienen todo este conjunto de iconos.

${ }^{8}$ Charles Morris, como también hiciera Sebeok, plantea "grados de iconicidad", citando como casos de blando iconismo las onomatopeyas verbales. Podríamos decir, entonces, que el cine es más icónico que la pintura. El aparentemente misterioso problema del icono se da cuando tanto Morris como también Peirce se plantean su definición en relación con un determinado objeto, "in some respects", sin dar nunca una explicación científica del hecho (Eco 1975: 258). Eco concluye que es más exacto afirmar que "los signos icónicos no tienen las mismas propiedades físicas del objeto, sino que estimulan una estructura perceptiva 'semejante' a la que sería estimulada por el objeto imitado" (ibid.). Su escaso grado de iconicidad está marcado por el hecho que el rostro del retratado es sustituido completamente por sus accesorios, por su disfraz. No estamos ante Walter White, sino ante su disfraz, es decir, Heisenberg. 
Asistimos a una condensación del relato en esta trinidad de elementos: el pork pie hat, las gafas de sol y el bigote-perilla están por todo el proceso de transformación ${ }^{9}$.

Por todo lo expuesto, deducimos que este conjunto de iconos funciona como un hipertexto de la serie, que sería su hipotexto. Siguiendo a Genette (1982: 14-15), definimos la relación del hipertexto con el hipotexto como vínculo de imitación o de transformación que engendra algo nuevo sin esconder lo que hay detrás. El hipotexto es el contenido del hipertexto, aquello que el hipertexto expresa o a lo que se refiere.

Un punto crucial del uso del término icono es que su definición se aleja gradualmente de la perspectiva peirceana. La teoría de Peirce se centra en la idea de semejanza a partir de su teoría de grafos, con la que analizaba los diagramas lógicos. Umberto Eco (1975: 256-284) critica la concepción ingenua del iconismo, según la cual el icono sería un signo motivado y no arbitrario, recordando que también la motivación es una convención, estableciendo que la noción de "convención" no es coextensiva a la de "arbitrariedad", sino a la de vínculo "cultural" (ivi: 256).

Las imágenes de Heisenberg son iconos también en el sentido peirceano. Pero también son algo más. Si en Real Diccionario de la Lengua las definiciones que encontramos se limitan a la citada más arriba ("signo que mantiene una relación de semejanza con el objeto representado") y a los iconos religiosos, en cambio el Oxford English Dictionary define 'cultural icon' como "a person or thing regarded as a representative symbol, especially of a culture or a movement; or an institution considered worthy of admiration or respect". Se confirma así que la imagen es en cierto grado un símbolo que requiere la sanción del público, es decir, de los consumidores.

En el mismo sentido se mueve Douglas B. Holt (2004: 2), quien en la introducción a su obra How Brands Become Icons? sostiene que los iconos son portadores de una importante carga simbólica:

Los iconos vienen a representar un tipo particular de historia de la identidad -uno de los mitos que los consumidores utilizan para hacer frente a sus deseos de identidad y a sus ansiedades. Los iconos tienen un valor extraordinario porque llevan una carga simbólica pesada para sus consumidores más entusiastas. Los iconos realizan un particular mito que la sociedad necesita especialmente en un momento histórico dado, y que lo realizan carismáticamente ${ }^{10}$.

Pero ¿qué contenidos poseen los iconos de Heisenberg? ¿Qué significados comparten con el hipotexto de donde emergieron inicialmente? Esta respuesta la podemos obtener si observamos las respuestas que algunos fans dieron a mi pregunta “¿por qué te consideras un fan de Heisenberg?”, que yo mismo lancé en la página Breaking Bad de Wikia, un dominio de tecnología wiki, es decir, de cooperación entre usuarios. Citaré solo dos ejemplos significativos:

\footnotetext{
${ }^{9}$ Un caso semejante es el de los ritos de la Verónica analizado por Calabrese (1995: 25): “En la Misa Gregoriana, en un determinado momento de la liturgia se mostraban, colgándolos junto al altar, los instrumentos de la pasión o la representación de los mismos (los clavos, la corona de espinas, la lanza del soldado y, claro está, la Verónica". La combinación de estos elementos significaba la pasión de Cristo. De manera similar, los elementos que hemos venido describiendo significan todo el proceso de cambio de Walter.

10 Traducción mía
} 
I admired his overwhelming desire to provide financial stability for his family. However, the demand for his skills elevated him from classic underachiever to rock star and the resulting egomania (I'm in the empire business) left him with nothing.

A complicated man with an 'addiction' for being the best at something, forgot or refused to acknowledge what was most important to him. I loved and pitied the character of Walter White.

He had all rights to be "prideful" and "ambitious". He was genious, purposeful person, who was the best in what he did. Not so many people could say this about themselves.

He had done many questionable decisions, that's right, but who we are to judge him? What you or me would have done in his skin? In those terrible and complicated circumstances? I can't say for sure and doubt you can ${ }^{11}$.

In the end, it's all about being happy, doing what you like/love to do, no matter what it is. Too many people in this world doing or living not the way they want to. Despite all evil deeds and broken lives, Walter White lived 2 years of incredible, adventurous life. Life which "served as a source" for one of the best stories ever made.

Maybe you could not call him a hero. I say he is more than that.

He's legend ${ }^{12}$.

Aparte del evidente tono enfático y eufórico de ambas respuestas, propias del consumidor descrito más arriba por Holt ${ }^{13}$, hay una serie de isotopías que aparecen en todas ellas y que delinean claramente los significados atribuidos a la figura de Heisenberg, o, en definitiva, a la transformación operada en el personaje. En ambos casos se justifican los actos cometidos por Heisenberg por el hecho de ser 'el mejor' o hacer lo que deseaba hacer. La satisfacción de hacer lo que se quiere en la vida parece ser el valor fundamental que encierra la figura de Heisenberg: el personaje está claramente modalizado por el querer-hacer.

Pero ¿qué hay del nombre propio 'Heisenberg'? ¿Aporta algún significado a la figura de nuestro personaje? Siendo Heisenberg un nombre propio, el plano del contenido solo puede establecerse por designación. Pero hay que tener en cuenta que se trata de un nombre de personaje histórico: cada enciclopedia nos dice todo lo que es

11 Traducción mía: “Admiro su abrumador deseo de proporcionar estabilidad financiera para su familia. Sin embargo, la demanda de sus habilidades lo elevó de bajo rendimiento clásico de estrella de rock y la egolatría resultante (que estoy en el negocio de imperio) lo dejó sin nada.

Un hombre complicado con una "adicción" por ser el mejor en algo, que le llevó a olvidarse o se negó a reconocer lo que era más importante para él. Me encantó y me apiadé del personaje de Walter White.

Él tenía todo derecho a estar "orgulloso" y ser "ambicioso". Él era un genio, una persona resuelta, que era el mejor en lo que hizo. No muchas personas pueden decir esto acerca de sí mismos.

Había hecho muchas decisiones cuestionables, es cierto, pero ¿cómo hemos de juzgarlo? ¿Lo que usted o yo habría hecho en su situación? ¿En esas circunstancias terribles y complicadas? No puedo decirlo con certeza y duda que usted pueda".

12 Traducción mía: "Al final, se trata de ser feliz, haciendo lo que te gusta/amas hacer, lo que quiera que seas. Demasiadas personas en este mundo haciendo o no vivir de la manera que quieren. A pesar de todas las malas acciones y vidas rotas, Walter White vivió 2 años de increíble vida, aventurero. La vida, que "sirve de inspiración" para una de las mejores historias jamás se ha contado.

Tal vez usted no lo podría llamar un héroe. Yo digo que es más que eso.

Él es una leyenda".

13 Tal es entusiasmo de los fans por Walter White que el año pasado se celebró el primer Festival Anual de fans de Breaking Bad, el Breaking Bad Fan Fest, en Albuquerque. Una de las actividades que allí se celebraron fue un concurso de parecidos: se buscaba al fan más parecido a Walter White aka Heisenberg. 
esencial saber para diferenciar la unidad cultural de un personaje histórico (cfr. Eco 1975: 143-144). En este caso, se hace pertinente el cuadrado que aparece en la figura 3 enmarcando las letras "He"14 del nombre junto al número dos: estamos ante la representación del elemento Helio junto a su peso atómico. Como si se tratase de un pasatiempo, la relación entre un elemento sintáctico y otro nos permite conquistar la solución: se trata de Werner Heisenberg, es decir, no se está indicando que el rostro representado es un tal Heisenberg cualquiera: /Este es Heisenberg/ o /Heisenberg es este/, sino que hay una analogía con un personaje histórico descrito anagráficamente. En realidad, se plantea una comparación: el rostro incógnito es el de alguien que mantiene una relación de semejanza con Heisenberg, como condensación abstracta de ambos relatos.

Coinciden letra y rostro-caricatura en un espacio indistinto. El distintivo topológico de la indicación de una doble lectura que reenvía al elemento Helio de la tabla periódica se realiza de dos formas: no solo por la línea que enmarca las letras "He", sino también por el cambio de tipografía de la letra. La escritura parece relacionarse con la imagen por obvias razones (¿es el nombre del sujeto representado?), pero además su composición nos reenvía también a los jeroglíficos de los periódicos. Los elementos incluidos hacen pensar que se oculta otro significado que, aparentemente, nada tiene que ver con lo que observamos directamente: la combinación de sombrero y gafas recuerda al camuflaje, la referencia a la tabla periódica sugiere una encriptación.

Se trata, por tanto, de una imagen esquemática, que recupera los procesos mismos de un tipo expresivo muy propio de nuestra cultura: el logotipo ${ }^{15}$. El icono de Walter White, en su simplicidad máxima, enuncia "yo soy un icono". No oculta su condición tras una pátina de realidad ilusoria. En este sentido, el trompe-l'oeil, epifanía del estímulo sucedáneo (Eco), estaría en el polo opuesto, ya que este niega su propia condición de icono (o hipoicono, en términos peirceanos). Así pues, se trata de una enunciación enunciada, pues, al contrario de lo que ocurre con el retrato realista o con el trompe-l'oeil, donde los signos aspiran a convertirse en cosa, aquí los signos se autodenuncian, distanciándose completamente de la cosa representada. Se trata de una representación que enuncia su condición misma de representación.

La cosa en una Vanitas es un mensaje encriptado, cifrado, es un mensaje que hay que descifrar, descodificar; una cosa en la Naturaleza muerta es una palabra. ¿Y en el trompel'oeil? Para Louis Marin [...] el signo de la cosa deviene la cosa misma (Lozano 2014: 12).

Aquí, los elementos elegidos para representar el objeto son mínimos: sombrero, gafas y perilla. En una cierta homología con la escritura, la combinación de elementos parece custodiar un enigma que el destinatario debe descifrar.

La escritura funciona como leyenda, como en el caso de los emblemas, las divisas o los epigramas, donde no solo acompaña sino que da la clave de lectura. Lo característico del emblema es el uso simultáneo de texto figurativo y verbal. La

14 En otros iconos también se enmarca la letra $\mathrm{H}$ del nombre Heisenberg, la cual hace referencia al hidrógeno de los elementos químicos (fig. 4). En este rasgo también podemos observar la isografía a la que hago referencia.

15 Otro ejemplo de emancipación de una parte de un texto audiovisual y su posterior proceso de simplificación propio de los logotipos, lo hallamos en La naranja mecánica. 
forma tradicional del emblema, consistente en un dibujo simbólico y de un lema, configura un complejo sistema de relaciones semánticas. De hecho, Lotman constata que en ocasiones el carácter de este sistema es tan complejo que puede acercarse a la poética del enigma, de cuyo hecho emerge la necesidad de un tercer texto (la fuente original de la leyenda) que aclare el significado, dando así la clave de lectura adecuada para la correlación entre dibujo y palabra. En este caso, el nivel de complejidad es máximo, ya que para tener la competencia interpretativa del mismo, debemos conocer el texto de origen o, al menos, tener un presente que se trata de un elemento perteneciente a toda una semiosfera textual.

Sea como fuere, detrás de esta trinidad de elementos icónicos isográficos (sombrero, gafas y bigote-perilla) se esconde no solo un hombre, Walter White, sino un conjunto de significados arrancados directamente de su texto fuente, Breaking Bad, y relacionados con el self-made man y el genio capaz de sobreponerse a las fatalidades hasta sentirse realizado.

\section{EL ICONO HEISENBERG A LA LUZ DE LA SEMIÓTICA DE LA CULTURA}

En sus trabajos, Yuri M. Lotman usa icono y símbolo como tipos de signos contrarios. El primero es no-discreto, mientras que el segundo es discreto, prácticamente ignorando así el índice o asignándole su función al icono. Fundamentalmente, además, Lotman trata el símbolo dentro de la tradición saussureana, es decir, como un signo convencional en el que se incluyen elementos de iconicidad (Lotman 1996: 155).

Lotman nunca escribió nada específicamente sobre el concepto de signo. Sin embargo, en muchos artículos, tanto Lotman como sus colegas de la Escuela de Tartu especificaron que usaban símbolo en un sentido distinto del de Peirce, definiéndolo en el contexto del mito: símbolo es una especie de micro-mito y el mito es un "símbolo con trama" (cfr. Semenenko 2012: 77).

El símbolo es, desde la óptica de la Escuela de Tartu, el significado de un elemento emblemático, que a su vez es siempre elemento de un determinado texto simbólico. Un grupo de elementos emblemáticos que forman cualquier frase simbólica es definido como emblema (cfr. ibid.: 70).

Aleksei Semenenko (2007) pone un ejemplo muy semejante al que analizo en el presente trabajo. Es el del personaje de Hamlet. La tragedia llega a funcionar como un modelo para la creación de otros textos, expandiéndose en numerosas traducciones a diferentes lenguas y miles de películas, producciones teatrales, parodias y otros textos que de alguna u otra manera se refieren al clásico shakespeareano. Sin embargo, cada director debe afrontar la historia de la obra y la crítica para poder presentar algo innovador.

Una de las consecuencias de la conversión del texto en modelo, según Semenenko, es que su estructura puede ser usada como un marco de referencia para acontecimientos culturales: el texto se convierte así en un "contenedor" donde en cada momento hay un nuevo contenido ${ }^{16}$. Cómo Hamlet es percibido como una

16 De hecho, Lotman sugirió la oposición entre textos religiosos y científicos, por una parte, y textos artísticos, por la otra. Mientras que en los primeros, cada interpretación se considera la única verdad y excluye a 
estructura está bien ilustrado por el uso que se hace de la obra en clave política, en el que el conflicto entre el héroe y "ellos" es dominante: Hamlet es retratado como un rebelde opuesto a la autoridad (o masas/convenciones) y es usado como un símbolo del inconformismo, del pensamiento liberal y de la disidencia. Aparecía en situaciones solo remotamente conectables a la tragedia, hasta el punto que en ocasiones la tragedia era usada como una forma de lenguaje esópico, una estructura canonizada donde creadores y traductores podían expresar su propia crítica o protesta (Semenenko 2007: 141-142).

Una de las imágenes más replicadas de Hamlet es la de The Poor Yorick. La imagen pertenece a un momento de la escena primera del Acto $\mathrm{V}$ en que Hamlet y su amigo Horacio ven cómo el enterrador desentierra los huesos de Yorick, el antiguo bufón de la corte. En ese momento, Hamlet observa la calavera y comienza un soliloquio en que recuerda las carcajadas que aquel bufón le arrancó en su infancia. La imagen es tan eficaz, que incluso en un grado mínimo de iconicidad inmediatamente se relaciona con el texto de Hamlet. Sin embargo, la imagen ha ido creando un vínculo cultural al monólogo To be or not to be, que se incluye en la escena tercera del Acto I. El caso es relevante para nuestro análisis, porque también en algunos de los casos de los iconos de Heisenberg aparece la frase I am the danger, 'yo soy el peligro', que, como ya dije en el primer epígrafe, Walter dice a su mujer en el sexto episodio de la cuarta temporada. Se trata por tanto de una enunciación enunciada: es Walter White aka Heisenberg, representada con su ya característica trinidad de elementos, quien dice 'yo soy el peligro'. Y, sin embargo, en ningún momento de la serie Walter dice esta frase ataviado con los accesorios propios de su alter ego. Más bien, al contrario, dice esta frase sin gafas ni sombrero. Como en el caso de la imagen Hamlet-Yorick, en los iconos I am the danger se han fundido dos elementos que actúan como memoria cultural del texto fuente: la imagen isográfica de Heisenberg y la célebre frase de la serie.

Por otra parte, uno de los factores es la temprana separación del personajeHamlet de la obra-Hamlet. El héroe se ha convertido en un lugar común hasta el punto de aparecer disociado de la obra de Shakespeare. Así se da nacimiento al fenómeno del Hamletismo, una tendencia a interpretar Hamlet como un símbolo, en el que se condensan ciertas características y que representa un cierto tipo de conducta. De hecho, otro semiólogo de Tartu, Iurii Levin (1977: 192), nos recuerda que la naturaleza del hamletismo es diferente al hecho de llamar a un marido celoso Othello o a un tirano sanguinario Ricardo III. Lo que se interpreta realmente es el personaje de Hamlet, no su trama. El fenómeno del Hamletismo es parte de lo que Lotman describe como el estrato mitológico de la cultura.

De la misma forma, en el caso del Hamletismo, Hamlet es un héroe solitario (y trágico) en conflicto con el mundo y/o consigo mismo que se encuentra en una posición de elección. Paralelamente, Heisenberg se trata de un personaje anticonformista situado ante en la misma posición de elección: como recordaba al inicio de este artículo, breaking bad se refiere a la idea de un camino equivocado.

las demás, en los segundos se da una acumulación de interpretaciones opuestas y contradictorias, pero que no se excluyen. En el primer caso estaríamos ante la relación aut/aut, mientras que en el segundo et/et. 
Así pues, nos percatamos que Heisenberg representa una estructura figurativa altamente replicable o reproducible (fig. 4), de una alta semioticidad y un alto grado aparente de polisemia. Tampoco es descartable que uno de los motivos de la eficacia de los iconos de Heisenberg lo encontremos en el principio de interactividad de Internet, según el cual el usuario deviene al mismo tiempo productor, es decir, un manipulador de las imágenes que recibe. De esta manera, el medio digital "exige del usuario $[\ldots]$ que mantenga la imagen en constante movimiento, que la transforme y que la componga de nuevo en cada momento" (Thürlemann 2004: 64). La sencillez de su estructura participa, sin duda, de su eficacia. Pero sin todos los contenidos que hallamos en la serie original sería imposible comprender el fenómeno.

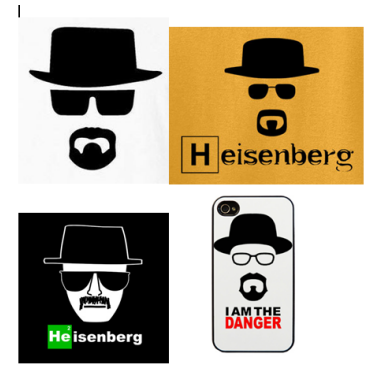

Figura 4. Diferentes réplicas de los iconos de Heisenberg.

\section{HEISENBERG Y LA EFICACIA ICÓNICA}

La gran fortuna iconográfica de Walter White aka Heisenberg no se debe al éxito de su indumentaria y sus accesorios faciales, por mucho que haya quienes han visto en ella la estética hipster. Antes bien, el éxito se debe a la eficacia ${ }^{17}$ con la que estos iconos isográficos y sus diferentes lemas han sabido canalizar significados culturalmente atribuidos a la figura de este personaje.

En nuestro caso, los iconos de Heisenberg son también un caso de eficacia donde se opera una evidente transformación semántica. Mientras en la serie se trata de un personaje que termina su vida matando por el placer de ser el mejor en lo que hace, los contenidos que eficazmente transmiten estos iconos son precisamente los de un

\footnotetext{
17 Desde su conferencia magistral "La eficacia icónica" en VII Congreso de la Asociación Internacional de Semiótica celebrado en México en 2003, Jorge Lozano ha insistido en este concepto en forma de perífrasis, que él mismo homologa al de "eficacia simbólica" de Lévi-Strauss (1958: 211-228), que no produce una relación de causa-efecto sino de significante-significado. En un artículo posterior, Lozano (2004: 130) puntualiza que la eficacia icónica pretende hacer referencia, de manera intuitiva, al efecto de construcción y destrucción de las imágenes. En concreto, en este último artículo estudia las imágenes de la caída de las torres del World Trade Centre de Nueva York y la transformación semántica de "accidente" en "atentado".
} 
personaje admirable por la capacidad de encontrar su propio camino y ser feliz haciendo lo que mejor sabe hacer. Heisenberg se ha convertido así en un icono cultural de una grandísima eficacia ${ }^{18}$. Su imagen trinitaria (sombrero-gafas-perilla) y sus lemas nos hablan de su transformación definitiva e irreversible. Walter era un don nadie. Heisenberg es el temible alter ego, un ser inigualable.

La eficacia de esta relación significante-significado se concentra en la capacidad de estos iconos de transmitir los contenidos relacionados con la percepción de la serie Breaking Bad, hasta el punto que su reducción en el grado de iconicidad no desvirtuaría en absoluto el contenido transmitido. Y aquí radica precisamente el poder cautivador de estos iconos: el fan siente que en estos iconos se condensa su propia percepción del contenido ostentado por el personaje. Y simultáneamente condensa valores de una cultura que lo convierten, igualmente, en un icono cultural.

\section{BIBLIOGRAFÍA}

CAlABRese, Omar (1995), “El trompe-l'oeil: ¿"engaño de los ojos"?”, en Baudrillard, Jean; Calabrese, Omar, El trompe l'oeil, Casimiro, Madrid 2014.

Eco, Umberto (1975), Tratado de semiótica general, Lumen, Barcelona 2000.

GenETte, Gérard (1982), Palimpsestos. La literatura en segundo grado, Taurus, Madrid 1989. Greimas, Algirdas J.; CourTÉs Jospeh (1979), Semiótica. Diccionario razonado de la teoría del lenguaje, Gredos, Madrid 1982.

HoLt, Douglas B. (2004), How Brands Become Icons?, Harvard Business School, Cambridge.

Levin, Iurii (1977), "Russian Hamletism”, en Lucid, Daniel (ed.), Soviet Semiotics, Johns Hopkins University Press, Baltimore, pp. 189-236.

LÉvi-Strauss, Claude (1958), Antropología estructural, Eudeba, Buenos Aires 1961.

LotMAn, Iurij M. (1993), Cultura y explosión. Lo previsible y lo imprevisible en los procesos de cambio social, Gedisa, Barcelona 1999.

Lotman, Iurij M. (1996), La semiosfera I. Semiótica de la cultura y del texto, Cátedra, Madrid.

LoZANO, Jorge (2004), "11-S todavía: semiótica del acontecimiento y explosión", en Cuadernos de Información y Comunicación CIC 9, pp. 129-136.

LoZANo, Jorge (2014), Introducción "Trampa ante los ojos", en Baudrillard, J.; Calabrese, O., El trompe-l'oeil, Casimiro, Madrid, pp. 7-17.

Peirce, Charles S. (1931-1935), Collected Papers, Harvard University Press, Cambridge.

SEвEOK, Thomas A. (1976), Contributions to the Doctrine of Signs, Indiana University Press, Bloomington.

SEDDA, Franciscu (2006), Introduzione "Imperfette traduzione", en Lotman, Jurij M., Tesi per una semiotica delle culture, Meltemi, Roma.

Semenenko, Aleksei (2007), Hamlet the Sign. Russian Translations of "Hamlet" and Literary Canon Formation, Almqvist \& Wiksel International, Estocolmo.

Semenenko Aleksei (2012), The Texture of Culture, Palgrave MacMillan, Nueva York.

${ }^{18}$ De igual forma, mientras que Hamlet era originalmente alguien que acababa en una vorágine vengativa, el Hamletismo se encargó de transformarlo en un modelo de conducta vinculado al héroe solitario y anticonformista que se enfrenta al mundo. 
Thürlemann, Felix (2004), "Dall'immagine all'iperimmagine", en Polacci, Francesca (a cura di), Carte semiotiche, n. 12, pp. 43-64 2011.

\title{
RESUMEN
}

El fenómeno fan art que se ha creado alrededor de la serie Breaking Bad, emitida por AMC entre 2008 y 2013, ha ido generando toda una serie de iconos de su protagonista, Walter White, encarnado por el actor Bryan Cranston. Los iconos que analizo en este trabajo guardan todos una isografía, un conjunto de elementos constantes en su composición sintáctica, y un claro homeomorfismo en su funcionalidad respecto al texto matriz de donde surgen. El interés de este trabajo se centra en la descripción tanto de sus características y funciones como de su surgimiento, hasta su conversión en lo que podríamos llamar un icono cultural.

Palabras clave: Breaking Bad, idonos, isografía, cultura.

\section{Walter White aka Heisenberg: the Rise of a Cultural Icon}

\begin{abstract}
The fan art phenomenon created around the TV series Breaking Bad, issued by AMC between 2008 and 2013, has generated a set of icons of its protagonist, Walter White, played by actor Bryan Cranston. The icons discussed in this paper keep a isography, a set of constant elements in their syntactic composition, and a clear homeomorphism in their functionality to the matrix text from which they arise. The interest of this work focuses on the description of both its features and functions and its emergence until its conversion into what might be called a cultural icon.
\end{abstract}

Keywords: Breaking Bad, icons, isography, culture.

\section{RÉSUMÉ}

Le phénomène de fan art qui a été créé autour de la série Breaking Bad, émise par AMC entre 2008 et 2013 , a généré une série complète d'icônes de son protagoniste, Walter White, joué par l'acteur Bryan Cranston . Les icônes que je discute dans le présent document ont chacun une isographie, un ensemble d'éléments constants dans leur composition syntaxique, et un homomorfisme clair dans la fonctionnalité par rapport au texte de la matrice à partir de laquelle ils surviennent. L'intérêt de ce travail se concentre sur la description de deux de ses caractéristiques et de fonctions et son émergence jusqu'à sa conversion en ce qu'on pourrait appeler une icône culturelle .

Mots-clé: Breaking Bad, icônes, isographie, culture . 